\title{
AXONAL TRANSPORT AND TRANSCELLULAR TRANSFER OF NUCLEOSIDES AND POLYAMINES IN INTACT AND REGENERATING OPTIC NERVES OF GOLDFISH: SPECULATION ON THE AXONAL REGULATION OF PERIAXONAL CELL METABOLISM ${ }^{1}$
}

\author{
N. A. INGOGLIA, ${ }^{* 2}$ S. C. SHARMA, $\ddagger$ J. PILCHMAN, ${ }^{* 3}$ K. BARANOWSKI, ${ }^{*}$ AND J. A. STURMAN§ \\ ${ }^{*}$ Departments of Physiology and Neuroscience, University of Medicine and Dentistry of New Jersey-New Jersey Medical \\ School, Newark, New Jersey 07103. $\ddagger$ Departments of Ophthalmology and Anatomy, New York Medical College, Valhalla, \\ New York 10595, and §Department of Pathological Neurobiology, Institute for Basic Research in Mental Retardation, Staten \\ Island, New York 10314
}

Received November 16, 1981; Revised April 30, 1982; Accepted May 7, 1982

\begin{abstract}
The axonal transport, metabolism, and transcellular transfer of uridine, adenosine, putrescine, and spermidine have been examined in intact and regenerating optic nerves of goldfish.

Following intraocular injection of labeled nucleosides, axonal transport was determined by comparing left-right differences in tectal radioactivity, and transcellular transfer was indicated by light autoradiographic analysis. The results demonstrated axonal transport, transcellular transfer, and periaxonal cell utilization of both nucleosides in intact axons and severalfold increases of all of these processes in regenerating axons.

Experiments in which the metabolism of the nucleosides was studied resulted in data which suggested that uridine and adenosine, when delivered to the tectum by axonal transport, are protected from degradation and thus are relatively more available for periaxonal cell utilization than nucleosides reaching these cells via the blood. In intact axons, the majority of the nonmetabolized radioactivity was present as UMP, UDP, and UTP following $\left[{ }^{3} \mathrm{H}\right]$ uridine injections, whereas the majority of the radioactivity following $\left[{ }^{3} \mathrm{H}\right]$ adenosine injections was present as adenosine, with the phosphorylated derivatives constituting a smaller proportion. During nerve regeneration, the relative proportion of nucleosides to nucleotides was reversed, with uridine being the principal labeled compound in the first case, and AMP, ADP, and ATP being the major labeled compounds in the latter case. The nucleosides also were found to be different from each other in that adenosine, but not uridine, can be laken up by optic axons and transported retrogradely from the tectum to retinal ganglion cell bodies in the eye.

Following intraocular injection of $\left[{ }^{3} \mathrm{H}\right]$ spermidine, radioactivity was transported to the optic tectum and transferred to tectal cells in the vicinity of the regenerating axons. Following $\left[{ }^{3} \mathrm{H}\right]$ putrescine injections, silver grains were found over periaxonal glia, but preliminary findings suggest that they are not present over tectal neurons nor over radial glial cells in the periependymal layers. Analysis of tectal radioactivity showed in each case that it was composed primarily of the injected compounds. These studies indicale that, following axonal transport, the polyamines do not remain within regenerating axons but are transferred to cells surrounding the axon.

On the basis of these and previous findings, we speculate that the axonal transport and transcellular transfer of uridine, adenosine, polyamines, and perhaps other small molecules are means of communication between axons and periaxonal cells; that the axon can affect RNA and protein synthesis in periaxonal cells by regulating the availability of these small molecules; and that, during nerve regeneration, the increased metabolic needs of periaxonal cells are met by an increased axonal supply of precursors (adenosine and uridine) and other molecules (polyamines) critical for protein synthesis.
\end{abstract}

\footnotetext{
${ }^{1}$ This work was supported by Grants EY 02887 and EY 01426 from the National Institutes of Health.

${ }^{2}$ To whom correspondence should be addressed at Department of Physiology, College of Medicine and Dentistry of New Jersey-New Jersey Medical School, 100 Bergen Street, Newark, NJ 07103.
}

\footnotetext{
${ }^{3}$ Medical student research fellow supported by a stipend from the Foundation of the College of Medicine and Dentistry of New Jersey and the Century Club of the Alumni Association of the New Jersey Medical School.
} 
A wide variety of molecules are delivered into an axon from a neuronal cell body and then moved along the axon by axonal transport. The substances transported, including both macromolecules and small molecules, generally are assumed to play important roles in maintaining the physical integrity of the axon as well as participating in the physiological activity of the neuron (for a comprehensive recent review of the subject, see Grafstein and Forman, 1980).

Proteins, the most widely studied of the macromolecules, are transported axonally, with a small component being transferred to postsynaptic neurons (transneuronal transport). The component transferred to postsynaptic neurons may be intact proteins or amino acids which then are incorporated into proteins in postsynaptic cells (Grafstein, 1971; Grafstein and Laureno, 1973; Heacock and Agranoff, 1977; Barber and Raisman, 1978). Except for the case of $\left[{ }^{3} \mathrm{H}\right]$ proline injected into the CNS of cats (Berkley et al., 1981), there have been no reports of a significant transfer of axonally transported proteins or of labeled amino acids from axons to periaxonal glial or Schwann cells (Barber et al., 1978; Griffin et al., 1976). This also appears to be the case for another macromolecule, $4 \mathrm{~S}$ RNA, which is transported along regenerating optic axons of goldfish (Gambetti et al., 1978; Ingoglia, 1982).

However, following the application of $\left[{ }^{3} \mathrm{H}\right]$ uridine to a neuronal cell body, labeled RNA is found primarily in Schwann or glial cells along the length of the axon (Peterson et al., 1968; Gambetti et al., 1973; Lindquist et al., 1981). In goldfish, this transfer of label from axon to glia is increased significantly during nerve regeneration (Ingoglia et al., 1975). There is also evidence for the transfer of axonally transported adenosine from axons to glia (Wise et al., 1978) and from axons to neurons (Schubert and Kreutzberg, 1974). Following the administration of $\left[{ }^{3} \mathrm{H}\right]$ choline (Droz et al., 1978) or $\left[{ }^{3} \mathrm{H}\right]$ serine (Haley and Ledeen, 1979) to a neuronal cell body, labeled phospholipids are found associated with the myelin sheath as well as with the axoplasm, indicating that, like nucleosides, choline and serine as well as phospholipids are transferred from axons to surrounding cells. This more general transfer of radioactivity from an axon to a variety of cells in the vicinity of the axon, rather than to specific postsynaptic neurons, has been termed "transcellular transfer" to distinguish it from the more specific transneuronal transfer described above for proteins (Wise et al., 1978).

In the present experiments, we have examined further the axonal transport and transcellular transfer of uridine and adenosine in the goldfish visual system and studied the changes in these processes occurring during nerve regeneration. In addition, we have studied the distribution following axonal transport of the diamine putrescine and the polyamine spermidine, small molecules which are transported axonally in regenerating optic nerves of the goldfish visual system (Ingoglia et al., 1977).

Our principal findings are that adenosine, like uridine, is transported axonally, transferred to periaxonal cells, and utilized by these cells for macromolecular synthesis in normal optic axons; that these processes are increased during nerve regeneration; and that, following axonal transport, putrescine and spermidine do not remain intra- axonal but, like nucleosides, are transferred from axons to periaxonal cells.

Based on these and other data, we speculate that the axonal transport, transcellular (ransfer, and periaxonal cell utilization of a variety of small molecules, including but not limited to those described above, represent a system whereby an axon can control or influence the metabolism of surrounding cells. This system, which has been suggested in part by others (Gambetti et al., 1973; Droz et al., 1978; Grafstein and Forman, 1980; Haley and Ledeen, 1979; Politis and Ingoglia, 1979), is proposed as a potentially critical element in the trophic regulation by axons of adjacent glial cells and postsynaptic neurons.

\section{Materials and Methods}

Goldfish (Carassius auratus, 10 to $12 \mathrm{~cm}$ in length) were obtained from Merrit Imports, Paramus NJ. Radioactive isotopes, $\left[{ }^{3} \mathrm{H}\right]$ adenosine $(14.2 \mathrm{Ci} / \mathrm{mmol}),\left[{ }^{3} \mathrm{H}\right]$ uridine $(30.0 \mathrm{Ci} / \mathrm{mmol}),\left[{ }^{3} \mathrm{H}\right]$ putrescine $(18.7 \mathrm{Ci} / \mathrm{mmol})$, and $\left[{ }^{3} \mathrm{H}\right]$ spermidine $(43.0 \mathrm{Ci} / \mathrm{mmol})$, were obtained from Amersham/Searle Corp., Arlington Heights, IL.

Injection and surgical procedures. To study anterograde axonal transport, $5 \mu \mathrm{l}(5 \mu \mathrm{Ci})$ of the radioactive compound was injected into the right eye as described previously (Ingoglia et al., 1973). For retrograde transport, injections were made intracranially according to the techniques of Agranoff and Klinger (1964). In experiments in which nerve regeneration was studied, fish were anesthetized by immersion for $5 \mathrm{~min}$ in ice water and the nerves were crushed under a dissecting microscope by compressing the optic nerve a few millimeters behind the eye with curved jeweler's forceps. In those experiments in which optic nerves were cut, the same procedure was used except that the nerves were transected completely using fine dissecting scissors.

Analysis of tissue radioactivity. At various times after the injection of labeled compounds, tecta were removed and analyzed for radioactivity in trichloroacetic acid (TCA)-soluble and -insoluble fractions. The TCA-insoluble material, or, in some cases, fresh tissue, was made suitable for liquid scintillation counting by dissolving it in a tissue solubilizer (Protosol, New England Nuclear, Boston, MA) for $1 \mathrm{hr}$ at $55^{\circ} \mathrm{C}$. All samples were acidified before counting and radioactivity was measured in a Beckman liquid scintillation counter.

To determine the degree of metabolism of the ${ }^{3} \mathrm{H}$ nucleosides, samples of TCA-soluble radioactivity were obtained from the right retina and left and right tecta 3 days after the injection into the right eye of either $\left[{ }^{3} \mathrm{H}\right]$ uridine or $\left[{ }^{3} \mathrm{H}\right]$ adenosine. Half of each sample was assayed directly for radioactivity, while the other half was lyophilized to dryness and then brought back to its original volume with distilled deionized $\mathrm{H}_{2} \mathrm{O}$. Samples were counted and the percentage of loss of radioactivity due to conversion to a volatile substance (probably ${ }^{3} \mathrm{H}_{2} \mathrm{O}$ ) was determined. The same procedure was applied to the injected nucleosides which were found to be free of volatile metabolites. In some experiments, nonlyophilizable TCA-soluble radioactivity was analyzed for phosphorylated derivatives by thin layer chromatography.

In experiments involving the polyamines, analysis of total radioactivity was done by digesting tissue samples 
in Protosol followed by liquid scintillation counting. To identify the nature of the radioactivity transported to the tectum, TCA-soluble extracts were analyzed using an amino acid analyzer in conjunction with a flow cell scintillation counter as described previously (Ingoglia et al., 1977).

Autoradiography. Fish with regenerating optic nerves were injected with $\left[{ }^{3} \mathrm{H}\right]$ adenosine, $\left[{ }^{3} \mathrm{H}\right]$ putrescine, or $\left[{ }^{3} \mathrm{H}\right]$ spermidine into the right eye and sacrificed 3 or 6 days later. Fish were perfused intracardially with goldfish Ringer's solution followed by $2.5 \%$ glutaraldehyde. Isolated pieces of tectum were immersed in fixative for $1 \mathrm{hr}$, osmicated, and processed for Epon embedding. One- to $2-\mu \mathrm{m}$ sections were prepared for autoradiography.

\section{Results}

The first experiments were performed to determine whether adenosine is transported axonally in the goldfish visual system and to study the effect of nerve regeneration on its axonal transport.

$\left[{ }^{3} \mathrm{H}\right]$ Adenosine was injected into the right eye of six normal fish (without regenerating optic nerves) and into the right eye of fish in which both optic nerves had been crushed 18 days prior to injection. Radioactivity in left and right tecta was assayed in TCA-soluble and -insoluble fractions at various times after injection. Since fibers from the right eye only project to the left tectum, significant differences in left versus right tectum radioactivity suggest axonal transport. The right tectum, on the other hand, receives no axonally transported radioactivity and serves as an index of the fate of injected material reaching the tectum via the general circulation.

The results showed significant differences in left versus right tectum radioactivity in TCA-soluble fractions of normal fish and a severalfold increase in this difference during regeneration of the optic nerves (Fig. $1 A$ ). This indicates that, following intraocular injection of $\left[{ }^{3} \mathrm{H}\right]$ adenosine, radioactivity is transported axonally in normal optic axons of goldfish and that the amount transported increases significantly during nerve regeneration. The TCA-insoluble fraction also exhibits left versus right differences in radioactivity (Fig. $1 B$ ). This could be due to either axonal transport of a labeled macromolecule or the axonal transport of adenosine (or a derivative) followed by its transfer to a periaxonal cell where it then is utilized for nucleic acid synthesis.

Autoradiographic data indicate that at least part of the insoluble fraction is due to the transfer of $\left[{ }^{3} \mathrm{H}\right]$ adenosine or a derivative to periaxonal cells and the incorporation of the radioactivity into nucleic acids (Fig. 2). In these experiments, optic nerves were crushed, and 18 days later, $\left[{ }^{3} \mathrm{H}\right]$ adenosine was injected into the right eye.

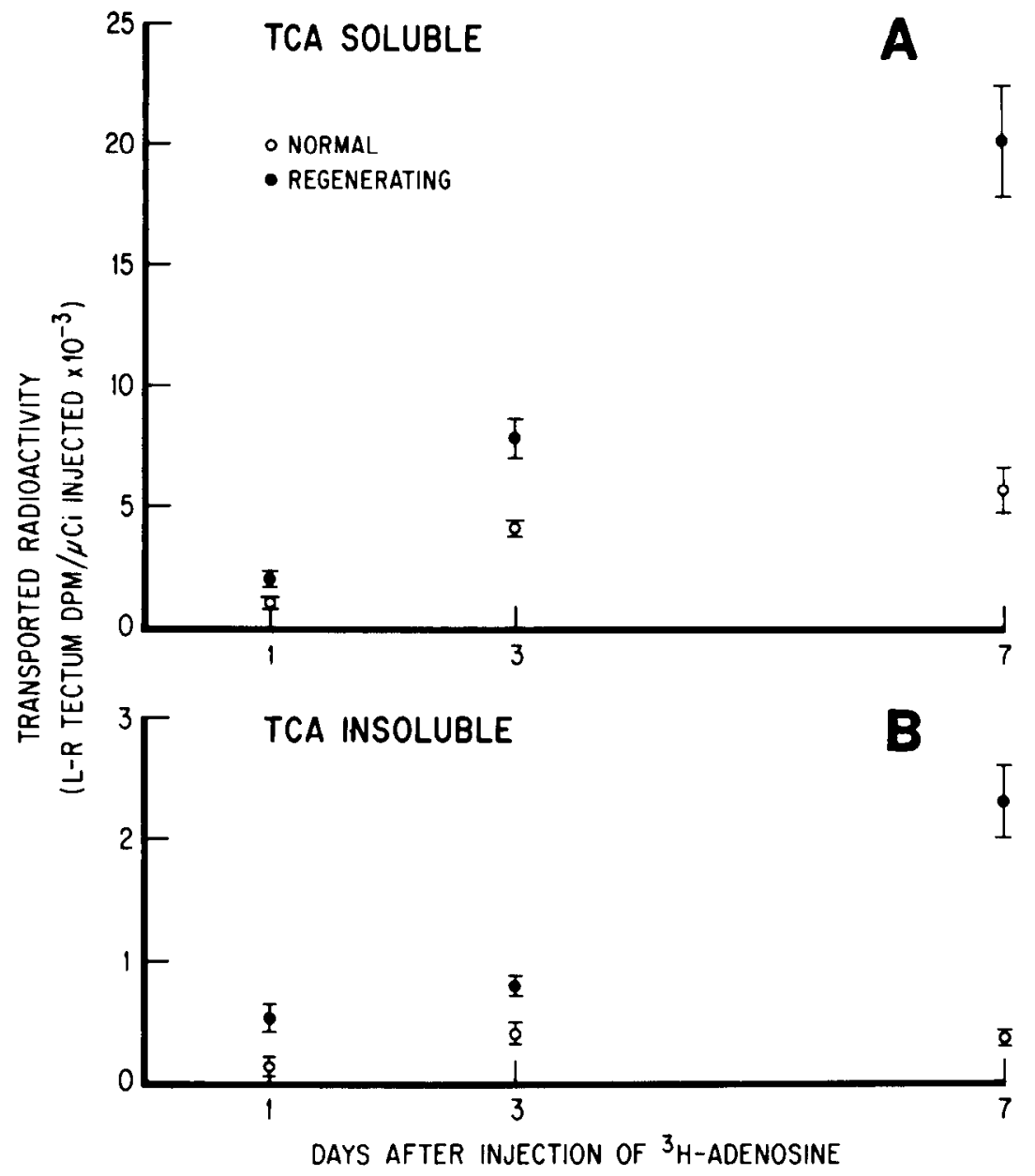

Figure 1. Radioactivity in TCA-soluble and -insoluble fractions in the goldfish optic tectum following the intraocular injection of $\left[{ }^{3} \mathrm{H}\right]$ adenosine. The regenerating values are from fish in which both optic nerves were crushed 18 days prior to injection. The values are means \pm SEM of four to six fish. 

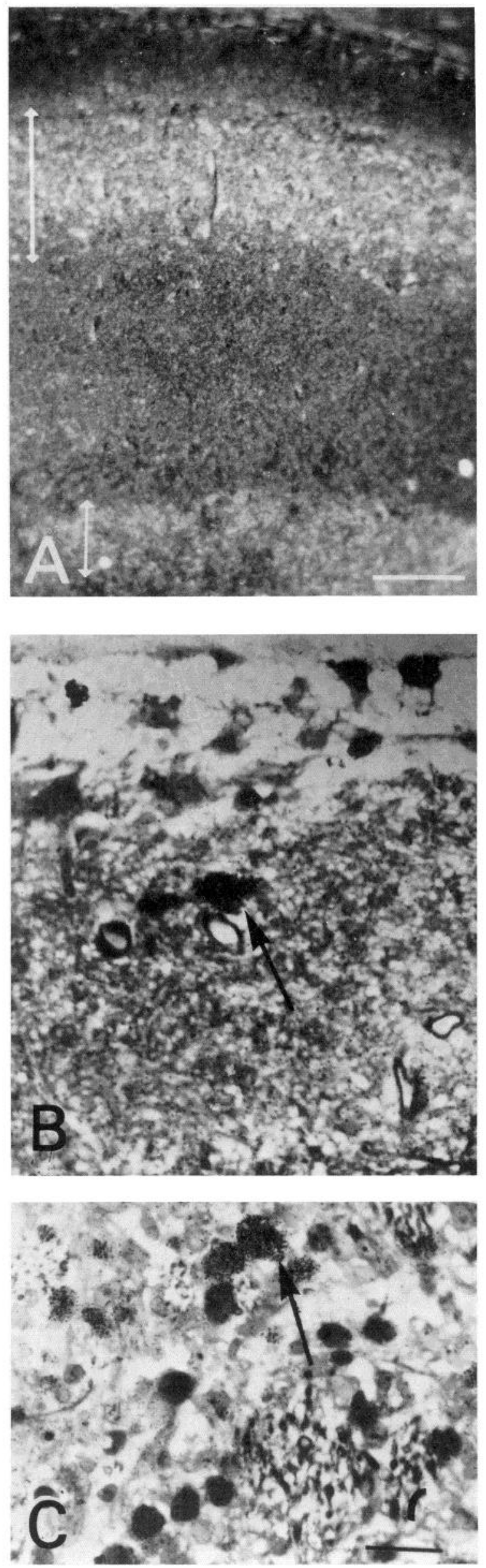

Fish were killed 6 days later and both optic tecta were processed for autoradiography. Negligible silver grains were found over the right optic tectum. However, the left tectum contained silver grains over the SFGS (strata fibrosum et griseum superficiale) as well as the SPV (stratum paraventricularis) (Fig. 2A). Grains (Fig. 2, $B$ and $C$ ) are clearly localized over cells in both regions. In the SFGS, these cells include both glia and neurons, while in the SPV, grains are primarily over postsynaptic neurons (Romeski and Sharma, 1979). In separate experiments, tectal radioactivity was analyzed for the presence of $\left[{ }^{3} \mathrm{H}\right] \mathrm{RNA}$ by tissue extraction and polyacrylamide tube gel electrophoresis as described elsewhere (Ingoglia, 1982). Approximately $50 \%$ of the radioactivity was associated with ribosomal RNA and the remainder was associated with 4 S RNA (data not shown). Using $\left[{ }^{3} \mathrm{H}\right]$ uridine as a precursor, other studies have shown that ribosomal RNA is derived only from periaxonal cells while $4 \mathrm{~S} \mathrm{RNA}$ is derived mainly from axons (Ingoglia, 1982). Thus, we conclude that a portion of the axonally transported $\left[{ }^{3} \mathrm{H}\right]$ adenosine, or a derivative, is transferred out of the axon to a variety of tectal cells; these cells then utilize transcellularly transferred precursors for nucleic acid synthesis.

The nature of the axonally transported TCA-soluble material following intraocular injection of $\left[{ }^{3} \mathrm{H}\right]$ adenosine or $\left[{ }^{3} \mathrm{H}\right]$ uridine was examined initially by determining what fraction of it had been converted to ${ }^{3} \mathrm{H}_{2} \mathrm{O}$. $\left[{ }^{3} \mathrm{H}\right]$ Uridine or $\left[{ }^{3} \mathrm{H}\right]$ adenosine was injected into the right eye, and 3 days later, the total TCA-soluble radioactivity and the radioactivity remaining after lyophilization were determined for the right retina and left and right tecta. The results showed that approximately $25 \%$ of the retinal radioactivity was lost as a result of lyophilization (Table I). While the percentage of loss of tectal radioactivity was somewhat different following the injection of either $\left[{ }^{3} \mathrm{H}\right]$ uridine or $\left[{ }^{3} \mathrm{H}\right]$ adenosine, in both cases, approximately twice as much radioactivity was lost from the right tectum compared with the left. Since the radioactivity in the right tectum is derived exclusively from the blood and left tectum radioactivity is largely a result of axonal transport, the data indicate that uridine and adenosine (or their derivatives), which are delivered to the tectum by axonal transport, are less susceptible to metabolic degradation than if they are delivered to the tectum via the blood.

The nature of the nonlyophilizable TCA-soluble material arriving in the optic tectum by axonal transport was determined by chromatography on polyethyleneimine/cellulose thin layer plates (Brinkmann) in a lithium chloride gradient (Spencer and Chargaff, 1963). In normal fish, radioactivity was found primarily as the phosphorylated derivatives of uridine, whereas during

Figure 2. Autoradiogram showing the labeled areas in the left optic tectum 21 days after both optic nerves were crushed and 6 days after $\left[{ }^{3} \mathrm{H}\right]$ adenosine was injected into the right eye. $A$ shows two areas (indicated by white double headed arrows) where the grain density is maximal. The upper area is the SFGS; the lower area is the SPV. $B$ and $C$ are high magnification photographs of the SFGS and SPV, respectively, showing heavily labeled cells (arrows) in both regions. Scale bars: $A$, $100 \mu \mathrm{m} ; B$ and $C, 20 \mu \mathrm{m}$. 
TABLE I

Effect of lyophilization on TCA-soluble radioactivity in retina and tecta 3 days after the injection of either [ $\left.{ }^{3} I I\right]$ uridine or $\left[{ }^{3} H\right] a d e n o s i n e$ into the right eye

The values are the means \pm SEM of four to six fish.

\begin{tabular}{|c|c|c|c|c|c|c|}
\hline & \multicolumn{3}{|c|}{$\left[{ }^{3} \mathrm{H}\right]$ Uridine } & \multicolumn{3}{|c|}{$\left[{ }^{3} \mathrm{H}\right]$ Adenosine } \\
\hline & Retina & Teft Tectum & Right. Tectum & Retina & I.eft Tectirm & Right Tectum \\
\hline & \multicolumn{6}{|c|}{$d p m / \mu C i$ injected } \\
\hline $\begin{array}{l}\text { Radioactivity remaining } \\
\text { after lyophilization }\end{array}$ & $13,616 \pm 1,813$ & $439 \pm 80$ & $48 \pm 9$ & $105,372 \pm 21,013$ & $3,453 \pm 395$ & $306 \pm 25$ \\
\hline
\end{tabular}

\section{LEFT TECTUM MINUS RIGHT TECTUM}
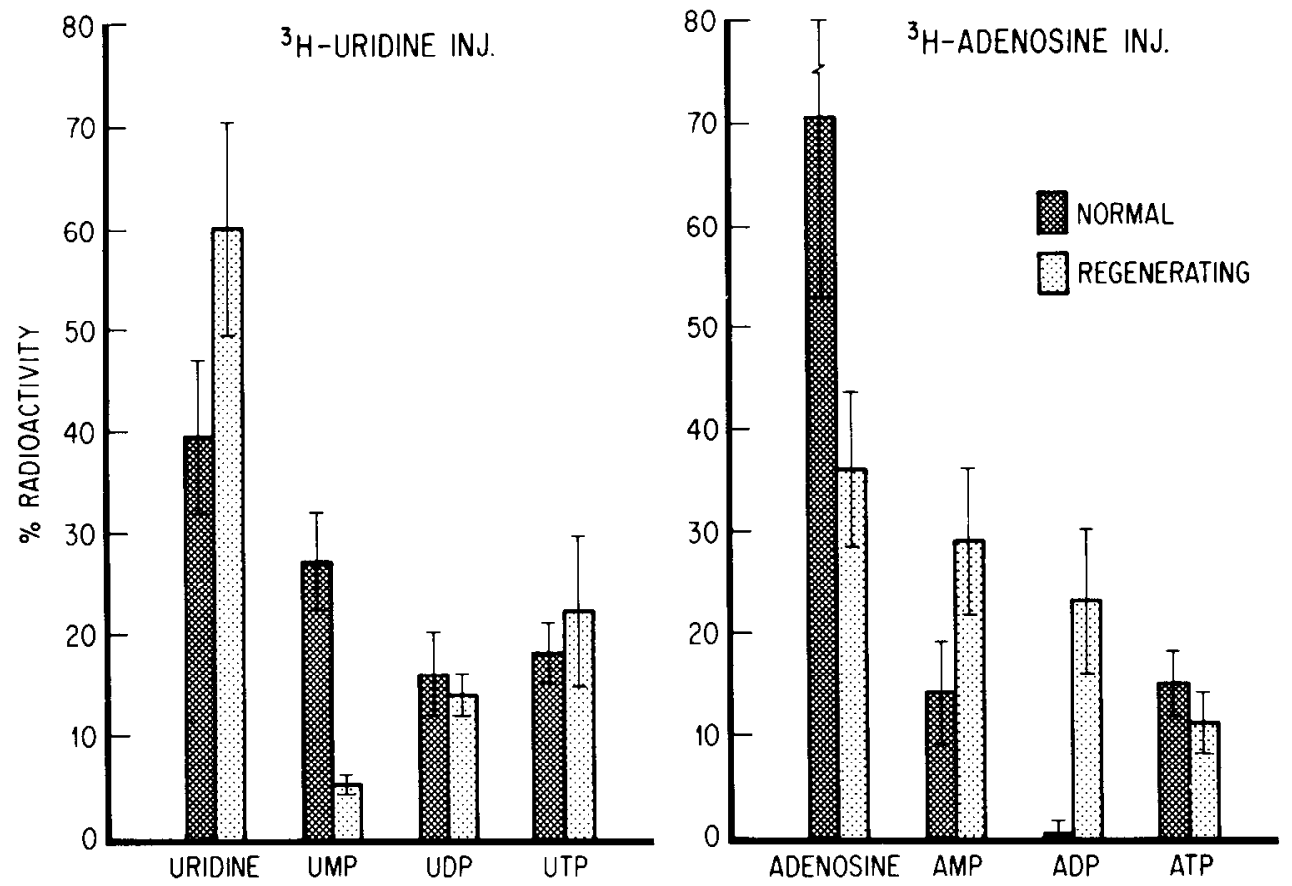

Figure 3. Thin layer chromatographic analysis of TCA-soluble radioactivity transported to the tectum 6 days after the intraocular injection of $\left[{ }^{3} \mathrm{H}\right]$ uridine or $\left[{ }^{3} \mathrm{H}\right]$ adenosine. The values are the means \pm SEM of three experiments.

nerve regeneration, a greater proportion was present as the parent, injected compound (Fig. 3). Following injections of $\left[{ }^{3} \mathrm{H}\right]$ adenosine, the inajority of the radioactivity transported is present as the parent compound, whereas during nerve regeneration, there is a greater conversion to the phosphorylated derivatives of adenosine (Fig. 3). Thus, while both adenosine and uridine are transported axonally, transferred to cells surrounding the axon, and utilized by these cells for nucleic acid synthesis, the profile of the TCA-soluble radioactivity arriving in the tectum is different for each.

The nucleosides also differ in that adenosine, but not uridine, can be taken up by optic axons (or axon terminals) and transported retrogradely back to the retina. This conclusion is based on data derived from experiments in which $5 \mu \mathrm{Ci}$ of either $\left[{ }^{3} \mathrm{H}\right]$ adenosine or $\left[{ }^{3} \mathrm{H}\right]$ uridine was injected intracranially, and at the same time, the right optic nerve was cut just behind the eye. One, 3 , or 7 days later, both retinae were removed and digested in Protosol, and radioactivity was determined in a liquid scintillation counter. Since the right nerve was cut, ra- dioactivity transported retrogradely can reach the left, but not the right, retina. Therefore, significant differences in left versus right retina radioactivity suggest retrograde axonal transport. Significant differences were found following intracranial injections of $\left[{ }^{3} \mathrm{H}\right]$ adenosine but not following injeclions of $\left[{ }^{3} \mathrm{H}\right]$ uridine (Fig. $4 A$ and $B$ ). This suggests that adenosine, but not uridine, is transported retrogradely. Since the right nerve was cut, it seemed possible that the retinal differences shown in Figure $4 A$ might be due to a decrease in the uptake of circulating $\left[{ }^{3} \mathrm{H}\right]$ adenosine by the cells of the axotomized right retina. If this was the case, then the same results should be obtained when $\left[{ }^{3} \mathrm{H}\right]$ adenosine is injected systemically. However, when $\left[{ }^{3} \mathrm{H}\right]$ adenosine was injected intraperitoneally, no difference was found in the amount of radioactivity taken up by each retina (Fig. $4 C$ ). Thus, we conclude that adenosine, but not uridine, can be taken up by axons or axon terminals and transported retrogradely along optic axons to retinal ganglion cells of the goldfish eye.

Next, an attempt was made to determine if polyamines, 

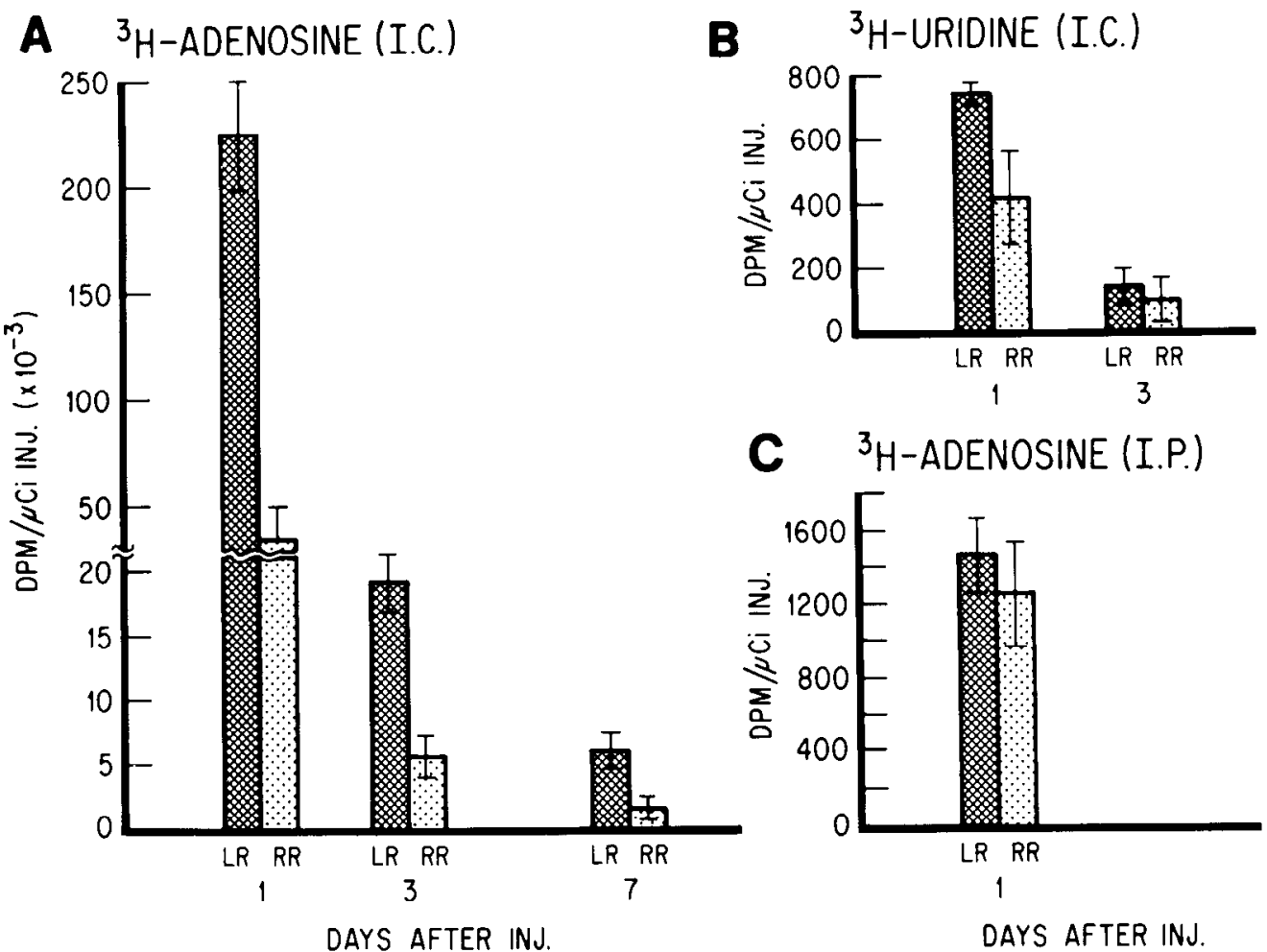

DAYS AFTER IN

DAYS AFTER INJ

Figure 4. Radioactivity present in the left and right retinae ( $L R$ and $R R$, respectively) of fish at various times after the intracranial $\left(A\right.$ and $B$ ) or intraperitoneal $(C)$ injection of $\left[{ }^{3} \mathrm{H}\right]$ adenosine or $\left[{ }^{3} \mathrm{H}\right]$ uridine. In $A$ and $B$, the right optic nerve was cut at the time of injection so that retrograde axonal transport is suggested by significant differences in left versus right retinal radioactivity. In $C$, the right optic nerve also was cut, but this did not affect the amount of $\left[{ }^{3} \mathrm{H}\right]$ adenosine accumulated from the general circulation by retinal cells. See the text for further details. The values are the means \pm SEM of four to six fish.

which are known to be transported axonally in this system, remain within axons following axonal transport or, like uridine and adenosine, are transferred out of the axon to periaxonal cells. Since, in goldfish, putrescine is transported only during optic nerve regeneration and the amount of spermidine transported is increased during nerve regeneration (Ingoglia et al., 1977), we have focused our attention on these two compounds. To determine if polyamines are transferred out of the axon following axonal transport, the tectal distribution of axonally transported radioactive polyainines was examined autoradiographically. In these experiments, both optic nerves were crushed and 18 days later, $\left[{ }^{3} \mathrm{H}\right]$ putrescine or $\left[{ }^{3} \mathrm{H}\right]$ spermidine was injected into the right eye. Fish were sacrificed 3 or 6 days later and tecta were prepared for light autoradiography as described under "Materials and Methods." Fixation with glutaraldehyde complexes the polyamines in situ so that they can be visualized when the tissues are processed for autoradiography.

Following injections of $\left[{ }^{3} \mathrm{H}\right]$ spermidine, few silver grains were found in the tectum ipsilateral to the injected eye. However, following injections of $\left[{ }^{3} \mathrm{H}\right]$ putrescine, a relatively high level of labeling was found over the right tectum. This indicates a delivery of radioactivity via the blood and is consistent with the finding that putrescine, but not spermidine, is able to cross the blood-brain barrier (Kremzner et al., 1970).

Following injections of $\left[{ }^{3} \mathrm{H}\right]$ putrescine, the tectum receiving axonally transported radioactivity contained silver grains primarily over the SFGS (Fig. 5A). Clear evidence was found for the presence of silver grains over glia in this region (Fig. $5 B$ ), but no grains above background were found over tectal neurons in the SFGS nor over tectal cells in the SPV. The data indicate that, following axonal transport, putrescine is transferred out of the axon to some periaxonal glial cells but may not be transferred to tectal neurons nor to radial glia in the SPV (Stevenson and Yoon, 1981). This possibility is currently being investigated. Following injections of $\left[{ }^{3} \mathrm{H}\right]$ spermidine, silver grains were found over the SFGS and SPV (Fig. 6A). In both layers, cellular elements were clearly labeled (Fig. $6 B$ and $C$ ). In the SPV, most cells, including radial glia, showed heavy labeling (Fig. $6 C$ ), unlike the results seen following putrescine injections. These preliminary findings suggest that, while spermidine is transferred to both glia and neurons, putrescine may be transferred only to specific glial cells (not radial glia in the SPV) and not to neurons.

Additional experiments were performed to be sure that the silver grains shown in Figures 5 and 6 originated from radioactive polyamines. Thus, the experiments described above were repeated except that, instead of analyzing the radioactivity by autoradiography, 24 tecta were pooled and TCA-soluble radioactivity was assayed using an amino acid analyzer. Virtually all of the radioactivity was present as putrescine, spermidine, or spermine in the proportions shown in Table II. This indicates that the radioactivity represented histologically by silver grains shown in Figures 5 and 6 originates from one of the polyamines and not from a nonpolyamine metabolite. 

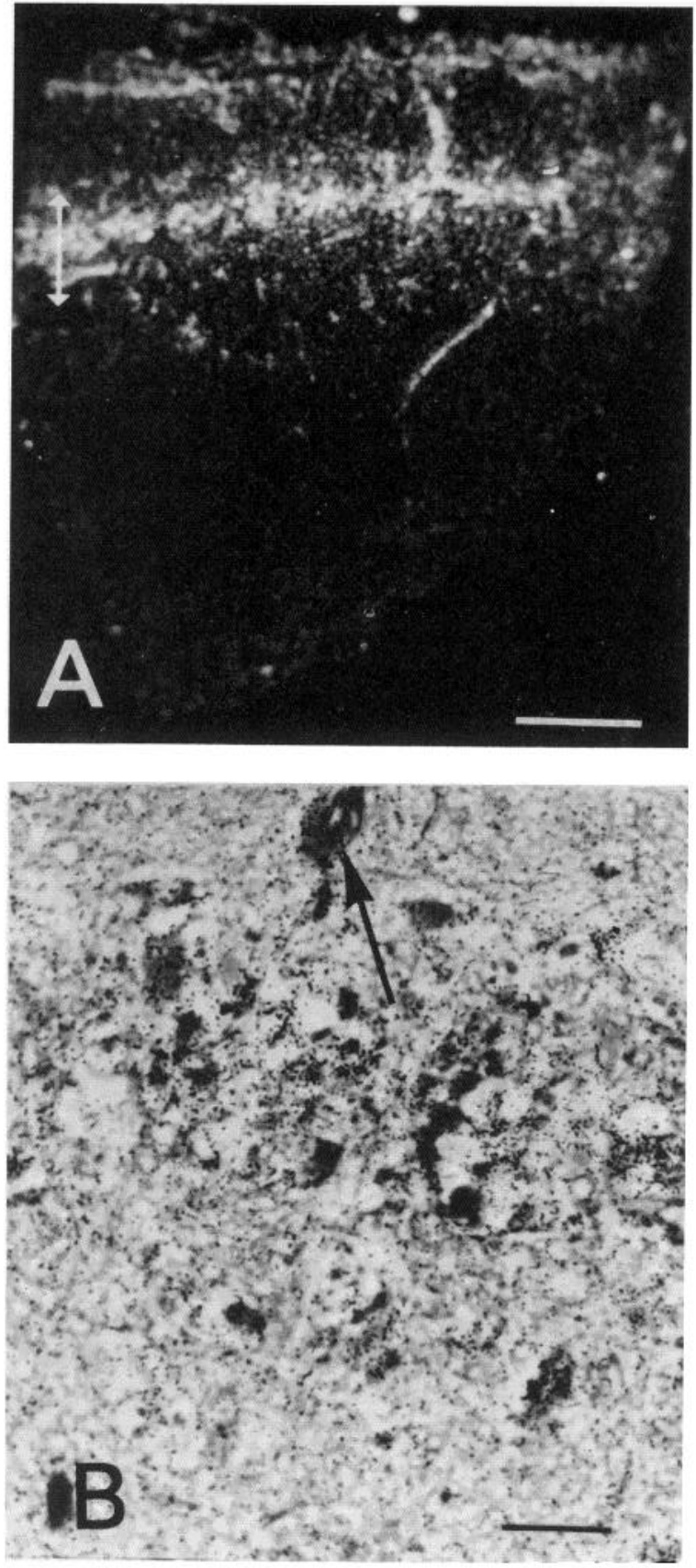

Figure 5. Autoradiogram showing the labeled areas in the left optic tectum 21 days after both optic nerves were crushed and 3 days after $\left[{ }^{3} \mathrm{H}\right]$ putrescine was injected into the right eye. $A$ shows grains concentrated over the SFGS (indicated by the white doubleheaded arrow) but not over the SPV. $B$ is a high magnification photograph of the SFGS showing a heavily labeled glial cell (arrow). Scale bars: $A, 100 \mu \mathrm{m} ; B, 20 \mu \mathrm{m}$.

Figure 6. Autoradiogram showing the labeled areas in the left optic tectum $(A) 24$ days after both optic nerves were crushed and 6 days after $\left[{ }^{3} \mathrm{H}\right]$ spermidine was injected into the right eye. The distribution of grains (white double headed arrows) is similar to that described in Figure 2, with cells labeled (arrows) in both the SFGS $(B)$ and SPV $(C)$. Scale bar: $A, 100 \mu \mathrm{m} ; B, 20 \mu \mathrm{m}$.
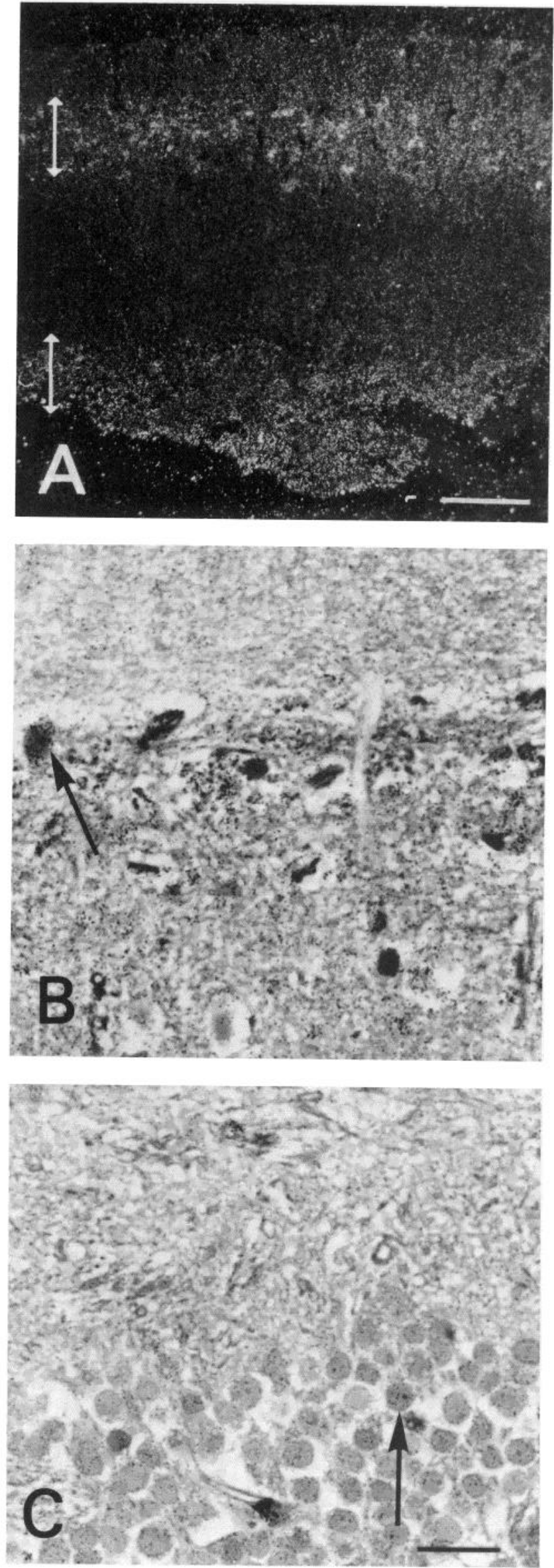
TABLE II

Distribution of radioactivity in the goldfish optic tectum 3 or 6 days after the intraocular injection of $\left[{ }^{3} \mathrm{H}\right]$ putrescine or $\left[{ }^{3} \mathrm{H}\right]$ spermidine

The values are the percentages of radioactivity associated with each of the polyamines.

\begin{tabular}{cccc}
\hline Injected Compound & Putrescine & Spermidine & Spermine \\
\hline $\begin{array}{c}\text { \% radioactivity } \\
\left.\text { [ }{ }^{3} \mathrm{H}\right] \text { Putrescine } \\
\quad \text { (3 days after injection) }\end{array}$ & 90.0 & 8.9 & 1.1 \\
$\begin{array}{c}\left.{ }^{3} \mathrm{H}\right] \text { Spermidine } \\
\text { (6 days after injection) }\end{array}$ & 10.0 & 70.0 & 20.0 \\
\hline
\end{tabular}

\section{Discussion}

These experiments describe the axonal transport and transcellular transfer of uridine, adenosine, putrescine, and spermidine in normal and regenerating optic nerves of goldfish.

\section{Uridine}

Uridine (or a nucleotide derivative) is transported axonally in the goldfish visual system, and the amount transported is increased significantly during nerve regeneration (Ingoglia et al., 1975). Changes in the amount of radioactivity transported in regenerating nerves may be due either to an increase in the uptake of the precursor with no change in the proportion transported or to a selective shunting of labeled precursors into the regenerating axons with or without a change in uptake. We cannot distinguish between these two possibilities in the present experiments. However, whichever is the case, it is clear that, during nerve regeneration, the metabolism of the retinal ganglion cell is altered so that increased amounts of labeled uridine (and the other precursors used in these experiments), enter into the regenerating axons and are delivered via axonal transport to the optic tecta.

Approximately $18 \%$ of the TCA-soluble radioactivity which appears in the tectum as a result of axonal transport (calculated by subtracting the radioactivity in the right tectum from that in the left) is present as a volatile metabolite (probably ${ }^{3} \mathrm{H}_{2} \mathrm{O}$ ) of the injected compound, while $80 \%$ of the soluble radioactivity arriving in the tectum by the blood (indicated by radioactivity in the right tectum) is volatile (Table I). This is also true in nerves which are regenerating (data not shown). These findings are similar to those reported in the visual system of rats (Politis and Ingoglia, 1979) and suggest that uridine is metabolized when it enters the general circulation, probably outside of the brain, but is protected from degradation when it reaches nervous tissue by axonal transport. Data obtained following similar experiments with $\left[{ }^{3} \mathrm{H}\right]$ adenosine (Table I) indicate that adenosine is also part of this protected intra-axonal pool.

In the optic nerve of the goldfish (Gambetti et al., 1978), chick (Por et al., 1978), rat (Politis and Ingoglia, 1979), and rabbit (Gambetti et al., 1973) and in the sciatic nerve of the chicken (Peterson et al., 1968; Gunning et al., 1979) and rat (Lindquist and Ingoglia, 1979; Lindquist et al., 1981), periaxonal cells utilize transcellularly transferred uridine for RNA synthesis. In the visual system of the neonatal rat, developmentally related "bursts" in
RNA synthesis in lateral geniculate cells are detected only when the labeled nucleosides are delivered from an axonally transported pool and not when they are derived from systemically available labeled precursors (Politis and Ingoglia, 1979). Data from the latter study was interpreted as indicating that, in the neonatal rat, the axonal delivery of uridine may be critical to support the increased metabolic demands of geniculate cells during the growth and maturation of optic axons. We suggest that, in the systems referenced above, where periaxonal cells utilize axonally transported $\left[{ }^{3} \mathrm{H}\right]$ uridine, the axon, at least in part, is meeting the demands for RNA precursors of periaxonal cells.

\section{Adenosine}

Following intraocular injections of $\left[{ }^{3} \mathrm{H}\right]$ adenosine, many of the findings obtained were similar to those reported for uridine. There is an axonal transport of TCA-soluble radioactivity which increases severalfold during nerve regeneration (Fig. $1 A$ ) and a transfer of radioactivity to periaxonal cells where it is utilized for nucleic acid synthesis (Figs. $1 B$ and 2). Since the TCAinsoluble fraction, which is found in the tectum as a result of axonal transport, also increases during nerve regeneration (Fig. $1 B$ ), we conclude that, like uridine, there is an increase in the transcellular transfer and utilization of adenosine (or a derivative) associated with the growth of the nerve.

The movement of axonally transported adenosine from the axon to neighboring cells has been reported previously (Schubert and Kreutzberg, 1974; Wise et al., 1978; Hunt and Kunzle, 1976; Kruger and Saporta, 1977). While the term "transneuronal" transfer has been applied to this phenomenon (Schubert and Kreutzberg, 1974), the balance of the data indicates that this term is too restrictive and that adenosine escapes from the axon to label a variety of cells in its vicinity, not only postsynaptic neurons (Hunt and Kunzle, 1976; Wise et al., 1978; see Fig. 2). Therefore, we agree with Wise et al. (1978) that a more appropriale term for the phenomenon is "transcellular" labeling. In this respect, except perhaps for the degree of transcellular transfer, uridine and adenosine appear to be handled similarly by most neurons.

The nucleosides are not handled similarly with regard to retrograde axonal transport. The experiments presented here indicate that adenosine, but not uridine, can be taken up by optic axons and transported back to retinal ganglion cells in the eye. The uptake of adenosine by synaptosomes has been demonstrated (reviewed by Stone, 1981) and its retrograde transport has been reported in a variety of systems (Hunt and Kunzle, 1976; Kruger and Saporta, 1977; Wise et al., 1978). The data of Wise et al. (1978) are similar to ours in that they too were unable to demonstrate a significant uptake or retrograde axonal transport of uridine. Those experiments were performed in chick and rat brain so that it seems likely that it is a general phenomenon of CNS neurons that adenosine, but not uridine, can be taken up by axons or axon terminals and transported retrogradely. The physiological significance of this cellular differentiation between the two nucleosides remains to be described. 


\section{Putrescine and spermidine}

Experiments examining the fate of axonally transported putrescine and spermidine indicate that, like uridine and adenosine, these amines undergo transcellular transfer following axonal transport. This conclusion is based on the autoradiograms shown in Figures 5 and 6. In the case of spermidine, the light labeling of the right tectum precludes the possibility that the labeling seen in cells in the tectum is due to blood-borne radioactivity. Thus, the silver grains derived mainly from $\left[{ }^{3} \mathrm{H}\right]$ spermidine (Table II) must have arisen from material which is transported axonally, some of which then is transferred to cells surrounding the axon. In the case of putrescine, labeling in the right tectum is significantly greater than that following $\left[{ }^{3} \mathrm{H}\right]$ spermidine injections. However, the grains in the left tectum are concentrated in the SFGS (Fig. 5A) and are frequently over cells in this layer (Fig. $5 B$ ). Therefore, it seems likely that, following the axonal transport of putrescine, a portion of the transported radioaclivity is transferred from axons to periaxonal cells. The finding that putrescine may be transferred only to certain glia and not to tectal neurons, while spermidine is transferred to both (compare Figs. 5 and 6 ) is currently under further investivation.

\section{Speculation on the significance of the axonal transport and transcellular transfer of small molecules}

Based on the current and previous findings, we propose: that the axonal transport and transcellular transfer of certain molecules is a significant physiological event; that this axonal supply system is responsible, at least in part, for meeting the metabolic demands of the cells (both glia and neurons) with which it comes in contact; that, during the growth of the axon (either development or regeneration), the altered metabolic needs of periaxonal cells are met in part by changes in the axonal transport and transcellular transfer of specific, critical molecules; and that, in this way, the axon is able to control or influence the metabolism of periaxonal cells. This system would form, at least in part, the biochemical basis for the "trophic" control that axons are able to exert on periaxonal cells. We base this hypothesis on the following observations and arguments.

The axonal transport of small molecules is not a random phenomenon. The neuronal cell body contains pools of small molecules, some of which are restricted to the soma, while others enter the axon and subsequently undergo axonal transport. Uridine, adenosine (see references above), spermidine, spermine (Ingoglia et al., 1977), taurine (Ingoglia et al., 1976b), and choline (Droz et al., 1978; Gould et al., 1979) pass into the axon from the soma, while most amino acids (Ochs et al., 1970; Karisson, 1977; but see Weiss et al., 1980; Beaudet et al., 1981) and putrescine in normal optic nerves of goldfish (Ingoglia et al., 1977) are restricted from entering the axon. A good example of the selectivity of the transport system is demonstrated in experiments in which radioactive cystathionine was injected into the goldfish eye and its axonal transport was examined (Ingoglia et al., 1978). When radioactivity in the retina was assayed, label was found associated with cystathionine, cysteine, protein, and taurine, with the latter being products of cystathionine metabolism. When radioactivity transported to the tectum was examined, radioactive taurine and protein, but not cysteine or cystathionine, were found. Thus, the retinal ganglion cell had "allowed" the sulfonic amino acid taurine to pass into the axon but did not allow the passage of cystathionine or cysteine. The evidence supports the concept of a selective gating mechanism between the cell body and the axon, a gate which allows the transport of certain small molecules (either as free molecules or bound to axonally transported macromolecules) but restricts the transport of others.

The axonal transport of small molecules is altered during the growth of the axon. The axonal transport of small molecules is affected by whether the axon is growing. When the nerve is elongating (during development or regeneration), there is an initiation of the flow of putrescine in goldfish optic nerves (Ingoglia et al., 1977); an increase in the amount of uridine (Ingoglia et al., 1975; Politis and Ingoglia, 1979), adenosine (these studies), and spermidine (Ingoglia et al., 1977) transported; a decrease in the proportion of spermine transported (Ingoglia et al., 1977); and no change in the amount of taurine transported (N. A. Ingoglia and J. A. Sturman, unpublished findings).

Thus, in a neuron capable of regeneration following axotomy, the cell body responds to injury by altering the nature or amount of small molecules transported. This may reflect a change in the synthesis of these molecules or an alteration in the selective gating mechanism. In the case of those molecules which are destined for utilization by periaxonal cells (uridine, adenosine, putrescine, and spermidine), we propose that the axon increases the transport of these molecules to either participate in the initiation of new genetic program (e.g., to induce glia to form channels for regenerating axons or to produce myelin) or to meet the increased metabolic demands of periaxonal cells.

The transcellular transfer of small molecules is not random: Not all small molecules present in the axon are transferred to periaxonal cells. A selective gating mechanism also is found for axonally transported materials between the axon and periaxonal cells. While it is known that there is some breakdown of transported labeled proteins along the length of the axon (Droz et al., 1973; Heacock and Agranoff, 1977), thus resulting in free amino acids in the axoplasm, and that some labeled amino acids are transported axonally (Weiss et al., 1980; Beaudet et al., 1981), there has been only one report of glial or Schwann cell protein labeling from labeled amino acids in axons. In these studies, $\left[{ }^{3} \mathrm{H}\right]$ proline, when injected into various nuclei of the cat CNS, was found to label glia along the length of the axon. The other amino acids tested labeled only axons as is the usual finding (Berkley et al., 1981). In squid axons, iontophoretically injected ${ }^{3} \mathrm{H}$-amino-acids only lightly labeled surrounding glia (Heuser and Miledi, 1970). In vertebrates, a careful analysis of tissue labeling following axonal transport of $\left[{ }^{3} \mathrm{H}\right]$ proline-labeled proteins in the mouse olfactory nerve showed significant transneuronal label, but virtually no label was found over glia (Barber et al., 1978). The reasons for the differences in these results and those of 
Berkley et al. (1981) remain to be explained. However, it appears that, under most conditions, amino acids are not transferred from axons to periaxonal glial cells.

Radioactive sugars used to study glycoprotein transport also remain intra-axonal and do not label myelin proteins or glycoproteins (Droz et al., 1973; Autilio-Gambetti et al., 1975; Matthieu et al., 1978; Tessler et al., 1980; Griffin et al., 1981). The same conclusion was reached with regard to axonally transported taurine; that is, following axonal transport, taurine is not transferred oul of the axon to surrounding cells (Ingoglia et al., 1978). Recently, studies involving $\left[{ }^{3} \mathrm{H}\right]$ thymidine injections into the goldfish eye have shown that thymidine is transported along optic axons and is incorporated into DNA in axonal mitochondria but is not transferred to periaxonal cells (P. Gambetti, personal communication).

Other molecules undergoing axonal transport are transferred transcellularly. Studies in the PNS (Droz et al., 1978) and CNS (Haley and Ledeen, 1979) have shown that both choline and serine, as well as phospholipids, can be transferred from the axon to supporting cells to be utilized in the formation of myelin lipids. Transported radioactivity also is transferred transcellularly following injections of adenosine, uridine, putrescine, or spermidine (see discussion above). Thus, the transcellular "gate" is open to some small molecules (adenosine, uridine, putrescine, spermidine, choline, and serine) but closed to others (most amino acids, including taurine, and thymidine). An alternative explanation, not ruled out by the current experiments, is that axons release all small molecules but that there is selective uptake of certain molecules by periaxonal cells.

The blood-brain barrier and active metabolism in the blood prevent some small molecules from getting to periaxonal cells from the general circulation, making these cells more dependent on an axon delivery system. A barrier exists to the passage of adenosine from the blood to brain cells (Berne et al., 1974). Following intracranial or intraventricular injections of $\left[{ }^{3} \mathrm{H}\right]$ uridine, radioactive RNA is localized to a large extent over pial and ependymal cells with only poor incorporation into neuronal or glial RNA (Ingoglia et al., 1976a). Thus, there appear to be barriers (blood-brain, cerebrospinal fluidbrain) to the entrance of uridine to glia and neurons from surrounding tissue. Kremzner et al. (1970) have described a blood-brain barrier to spermidine but not putrescine and this fits our data. In support of our current hypothesis, we argue that these molecules are less accessible or are inaccessible to brain cells when delivered by the blood but are readily accessible and utilized when delivered to cells by axonal transport. The finding that both uridine and adenosine are less likely to be metabolized during transit in the axon compared with distribution via the blood (see Table I; Politis and Ingoglia, 1979) supports this idea.

In summary, we propose that, under normal physiological conditions, the axon "feeds" critical small molecules to periaxonal cells by axonal transport followed by transcellular transfer. These molecules are not available (or are available in limited supply) from the blood because of the blood-brain barrier or active metabolism in the blood, and thus, periaxonal cells are, to some extent, metabolically dependent on the axonal delivery of these molecules. Further, we propose that the "trophic" control exerted by axons over postsynaptic neurons or glia is due, at least in part, to the axon's role in regulating the availability of these molecules to these cells. In cases of an altered functional state of the axon (during development or nerve regeneration, for example), the new metabolic "needs" of periaxonal cells are met, at least in part, by supplies arriving by axonal transport along regenerating axons.

More specifically, we reason that, in the case of nucleosides, uridine and adenosine are being transported axonally not because of the specific requirements of the axon but rather because the axon is supplying them to periaxonal cells for RNA synthesis. Thus, axonally derived RNA precursors may be rate limiting to cells which cannot accumulate significant amounts of the nucleosides from the blood or from de novo synthesis. This seems to be a reasonable possibility since, in several other systems, the synthesis of nucleic acids has been shown to be influenced by nucleotide concentration (Friedland, 1974; Lowry et al., 1977).

In the case of polyamines, we speculate that they too are transported axonally not for an intra-axonal purpose but rather for delivery to periaxonal cells, where they are to be used as they are in other cells as essential participants in nucleic acid and protein synthesis (Bachrach, 1973). The delivery of polyamines from axons to periaxonal cells is particularly intriguing because of their role in gene expression (Kramer et al., 1979; Morch and Benicourt, 1970; Das and Kanungo, 1979), their part in tRNA synthesis (Lovgen et al., 1978; Morch and Benicourt, 1970; Quigley et al., 1978), and their regulatory functions during translation (Goertz, 1979; Kramer et al., 1979).

This axonal delivery system may form part of the biochemical basis for the transformation of a glial scar into a glial channel by a regenerating axon (Reier, 1979), the general axonal "guidance" phenomenon attributed to glia in development and regeneration (Singer et al., 1979), the mitotic induction of radial glial cells by regenerating optic axons of goldfish (Stevenson and Yoon, 1981), and the axonal determination of myelinogenesis (Spencer and Weinberg, 1978).

Finally, we view the phenomena described in this paper as a limited component of a larger system of "metabolic cooperation" between axons and periaxonal cells. This system may involve not only the transcellular transfer of nucleosides and polyamines but also of lipids and other molecules not yet identified to a variety of periaxonal cells as well as the reverse transfer from glia to axons. The anatomical substrate mediating the transfer of molecules between axons and periaxonal cells is not known. However, the recent description of "pores" between axons and glia in crayfish (Peracchia, 1981) could serve this purpose if these channels are found to be present between vertebrate axons and glia.

\section{References}

Agranoff, B. W., and P. D. Klinger (1964) Puromycin effect on memory fixation in the goldfish. Science 146: 952-953.

Autilio-Gambetti, L., P., Gambetti, and B. Shafer (1975) Glial 
and neuronal contribution to proteins and glycoproteins recovered in myelin fractions. Brain Res. 84: 336-340.

Bachrach, U. (1973) Function of the Naturally Occurring Polyamines, Academic Press, New York.

Barber, P. C., and G. Raisman (1978) Inhibition by puromycin of transneuronal transport in the mouse accessory olfactory bulb. Brain Res. 152: 303-311.

Barber, P. C., D. M. Parry, P. M. Field, and G. Raisman (1978) Electron microscopic autoradiographic evidence for specific transneuronal transport in the mouse accessory olfactory bulb. Brain Res. 152: 283-302.

Beaudet, A., A. Burkhalter, J. -C. Reubi, and M. Cuenod (1981) Selective bidirectional transport of ${ }^{3} \mathrm{H}$-aspartate in the pigeon retino-tectal pathway. Neuroscience 6: 2021-2034.

Berkley, K. J., N. Contos, and H. H. Molinari (1981) Further evidence related to a possible macroglial cell involvement in the transfer of ${ }^{3} \mathrm{H}$-proline-labeled molecules along fiber tracts in the central nervous system of the cat. Part II. Soc. Neurosci. Abstr. 7: 699.

Berne, R. M., R. Rubio, and R. R. Curnish (1974) Release of adenosine from ischemic brain. Circ. Res. 35: 262-271.

Das, R., and M. S. Kanungo (1979) Effects of polyamines on "in vitro" phosphorylation and acetylation of histones of the cerebral cortex of rats of various ages. Biochem. Biophys. Res. Commun. 90: 708-714.

Droz, B., H. L. Koenig, and L. DiGiamberardino (1973) Axonal migration of protein and glycoprotein to nerve endings. I. Radioautographic analysis of the renewal of protein in nerve endings of chicken ciliary ganglion after intracerebral injection of ${ }^{3} \mathrm{H}$-lysine. Brain Res. 60: 93-127.

Droz, B, L. DiGiamberardino, H. L. Koenig, J. Boyenwal, and R. Hassig (1978) Axon-myelin transfer of phospholipid components in the course of their axonal transport as visualized by radioautography. Brain Res. 155: 347-353.

Friedland, A. (1974) Effect of methotrexate on deoxyribonucleotide pools and DNA synthesis in human lymphocytic cells. Cancer Res. 34: 1883-1888.

Gambetti, P., L. Autilio-Gambetti, B. Shafer, and L. Pfaff (1973) Quantitative autoradiographic study of labeled RNA in rabhit optic nerve after intraocular injection of ${ }^{3} \mathrm{H}$-uridine. J. Cell Biol. 59: 677-684.

Gambetti, P., N. A. Ingoglia, L. Autilio-Gambetti, and P. Weis (1978) Distribution of ${ }^{3} \mathrm{H}$-RNA in goldfish optic tectum following intraocular or intracranial injection of ${ }^{3} \mathrm{H}$-uridine. Evidence of axonal migration of RNA in regenerating optic. fibers. Brain Res. 154: 285-300.

Goertz, B. (1979) Effect of polyamines on cell-free protein synthesizing systems from rat cerebral cortex, cerebellum and liver. Brain Res. 173: 125-135.

Gould, R., R. S. Sinatra, W. Spivack, W. Berti, H. Wisniewski, T. Lindquist, and N. Ingoglia (1979) Axonal transport of phospholipids in rat sciatic nerve. Soc. Neurosci. Abstr. 5: 60.

Grafstein, B. (1971) Transneuronal transfer of radioactivity in the central nervous system. Science 172: 177-179.

Grafstein, B., and D. S. Forman (1980) Intracellular transport in neurons. Physiol. Rev. 60: 1167-1283.

Grafstein, B., and R. Laureno (1973) Transport of radioactivity from eye to visual cortex in the mouse. Exp. Neurol. 39: 4457.

Griffin, J. W., D. B. Drachman, and D. L. Price (1976) Fast axonal transport in motor nerve regeneration. J. Neurobiol. 7: 355-370.

Griffin, J. W., D. L. Price, D. B. Drachman, and J. Morris (1981) Incorporation of axonally transported glycoproteins into axolemma during nerve regeneration. J. Cell Biol. 88: 205-214.

Gunning, P. W., S. B. Por, C. J. Langford, J. Scheffer, L. Austin, and P. L. Jeffrey (1979) The direct measurement of the axoplasmic transport of individual RNA species. Transfer but not ribosomal RNA is transported. J. Neurochem. 32: 17371743.

Haley, P. E., and R. W. Ledeen (1979) Incorporation of axonally transported substances into myelin lipids. J. Neurochem. 32: 735-742.

Heacock, A. M., and B. W. Agranoff (1977) Revitalization of precursor following axonal transport of $\left[{ }^{3} \mathrm{H}\right]$ proline-labeled protein. Brain Res. 122; 243-254.

Heuser, J., and R. Miledi (1970) Autoradiography of labelled amino acids injected iontophoretically into the giant squid synapse. J. Physiol. (Lond.) 208: 55P-57P.

Hunt, S. P., and H. Kunzle (1976) Bidirectional movement of label and transneuronal transport phenomena after injection of ${ }^{3} \mathrm{H}$-adenosine into the central nervous system. Brain Res. 112: 127-132.

Ingoglia, N. A. (1982) $4 \mathrm{~S}$ PNA in regenerating optic axons of goldfish. J. Neurosci. 2: 331-338.

Ingoglia, N. A., B. Grafstein, B. S. McEwen, and I. G. McQuarrie (1973) Axonal transport of radioactivity in the goldfish optic system following intraocular injection of labeled RNA precursors. J. Neurochem. 20: 1605-1615.

Ingoglia, N. A., P. Weis, and J. Mycek (1975) Axonal transport of RNA during regeneration of the optic nerves of goldfish. J. Neurobiol. 6: 549-563.

Ingoglia, N. A., L. C. Sellin, and T. D. Lindquist (1976a) The effect of cordycepin on the appearance of ${ }^{3} \mathrm{H}$-RNA in the goldfish optic tectum following intraocular injection of ${ }^{3} \mathrm{H}$ uridine. J. Neurochem. 127: 179-184.

Ingoglia, N. A., J. A. Sturman, T. D. Lindquist, and G. E. Gaull (1976b) Axonal migration of taurine in the goldfish visual system. Brain Res. 115: 535-539.

Ingoglia, N. A., J. A. Sturman, and R. A. Eisner (1977) Axonal transport of putrescine, spermidine and spermine in normal and regenerating goldfish optic nerves. Brain Res. 130: 433445.

Ingoglia, N. A., J. A. Sturman, D. K. Rassin, and T. D. Lindquist (1978) A comparison of the axonal transport of taurine and proteins in the goldfish visual system. J. Neurochem. 31: 161170 .

Karlsson, J. O. (1977) Is there an axonal transport of amino acids? J. Neurochem. 29: 615-617.

Kramer, G., O. W. Odom, and B. Hardesty (1979) Polyamines in eukaryotic peptide initiation. Methods Enzymol. 11: 555566.

Kremmer, I. T., R. E. Barrett, and M. J. Terrano (1970) Polyamine metabolism in the central and peripheral nervous system. Ann. N. Y. Acad. Sci. 171: 735-748.

Kruger, L., and S. Saporta (1977) Axonal transport of ${ }^{3} \mathrm{H}$ adenosine in visual and somatosensory pathways. Brain Res. 122: $132-136$.

Lindquist, T. D., and N. A. Ingoglia (1979) Evidence that $4 \mathrm{~S}$ RNA is axonally transported in normal and regenerating rat sciatic nerves. Brain Res. 166: 95-112.

Lindquist, T. D., N. A. Ingoglia, and R. Gould (1981) 4S RNA is transported axonally in normal and regenerating axons of the sciatic nerve of rats. Brain Res. 230: 181-194.

Lovgren, T. N. E., A. Peterson, and R. B. Loftfield (1978) The mechanism of aminoacylation of transfer RNA. J. Biol. Chem. 253: 6702-6710.

Lowry, O. H., S. J. Berger, M. -Y. Chi, J. C. Carter, A. Blackohaw, and W. Outlaw (1977) Diversity of metabolic patterns in human brain tumors. I. High energy phosphate compounds and basic composition. J. Neurochem. 29: 959-977.

Matthieu, J. M., H. DeF. Webster, G. H. Devries, S. Corthay, and B. Kollreutter (1978) Glial versus neuronal origin of myelin proteins and glycoproteins studied by combined intraocular and intracranial labeling. J. Neurochem. 31: 93-102.

Morch, M. D., and C. Benicourt (1970) Polyamines stimulate 
suppression of amber termination codons "in vitro" by normal tRNAs. Eur. J. Biochem. 105: 445-451.

Ochs, S., M. I. Sabri, and N. Ranish (1970) Somal site of synthesis of fast transported materials in mammalian nerve fibers. J. Neurobiol. 1: 329-344.

Peracchia, C. (1981) Direct communication between axons and sheath cells in crayfish. Nature 290: 597-598.

Peterson, J. A., J. J. Bray, and L. Austin (1968) An autoradiographic study of the flow of protein and RNA along peripheral nerve. J. Neurochem. 15: 741-745.

Politis, M., and N. A. Ingoglia (1979) Axonal transport of nucleosides, nucleotides and 4S RNA in the neonatal rat visual system. Brain Res. 169: 343-356.

Por, S., P. W. Gunning, P. L. Jeffrey, and L. Austin (1978) The axoplasmic transport of $4 \mathrm{~S}$ RNA in the chick optic system. Neurochem. Res. 3: 411-422.

Quigley, G. J., M. M. Teeter, and A. Rich (1978) Structural analysis of spermine and magnesium ion binding to yeast phenylalanine transfer RNA. Proc. Natl. Acad. Sci. U. S. A. 75: 64-68.

Reier, P. J. (1979) Penetration of grafted astrocytic scars by regenerating optic nerve axons in Xenopus tadpoles. Brain Res. 164: 61-68.

Romeski, M., and S. C. Sharma (1979) The goldfish optic tectum. A. Golgi study. Neuroscience 4: 625-642.

Schubert, P., and G. W. Kreutzberg (1974) Axonal transport of adenosine and uridine derivatives and transfer to postsynaptic neurons. Brain Res. 76: 526-530.

Singer, M., R. H. Norlander, and M. Egar (1979) Axonal guid- ance during embryogenesis and regeneration in the spinal cord of the newt: The blueprint hypothesis of neuronal pathway patterning. J. Comp. Neurol. 185: 1-22.

Spencer, J. H., and E. Chargaff (1963) Studies on the nucleotide arrangement in deoxyribonucleic acids. Biochim. Biophys. Acta 68: 9-17.

Spencer, P. S., and H. J. Weinberg (1978) Axonal specification of Schwann cell expression and myelination. In Physiology and Pathobiology of Axons, S. G. Waxman, ed. 389-405, Raven Press, New York.

Stevenson, J. A., and M. G. Yoon (1981) Mitosis of radial glial cells in the optic tectum of adult goldfish. J. Neurosci. 1: 862875.

Stone, T. W. (1981) Physiological roles for adenosine and adenosine 5'triphosphate in the nervous system. Neuroscience 6: 523-555.

Tessler, A., L. Autilio-Gambetti, and P. Gambetti (1980) Axonal growth during regeneration: A quantitative autoradiographic study. J. Cell Biol. 87: 197-203.

Weiss, D. G., G. Schmid, and W. Lothar (1980) Influence of microtubule inhibitors on axoplasmic transport of free amino acids. Implications for the hypothetical transport mechanism. In Microtubules and Microtubule Inhibitors, M. DeBrabander and J. DeMey, eds., pp. 31-41, Elsevier/NorthHolland Biomedical Press, Amsterdann.

Wise, S. P., E. G. Jones, and N. Berman (1978) Direction and specificity of the axonal and transcellular transport of nucleosides. Brain Res. 139: 197-217. 